\title{
Activation of nicotinic acetylcholine receptor prevents the production of reactive oxygen species in fibrillar $\beta$ amyloid peptide (1-42)-stimulated microglia
}

\author{
Ju Hyun Moon ${ }^{1,2}$, Soo Yoon $\mathrm{Kim}^{1,2}$, \\ Hwan Goo Lee ${ }^{1,2}$, Seung U. Kim ${ }^{3,4}$ \\ and Yong Beom Lee $e^{1,2,3,5}$ \\ ${ }^{1}$ Neuroscience Graduate Program \\ ${ }^{2}$ BK21 Division of Cell Transformation and Restoration \\ ${ }^{3}$ Brain Disease Research Center \\ Ajou University School of Medicine \\ Suwon 443-721, Korea \\ ${ }^{4}$ Division of Neurology, Department of Medicine \\ University of British Columbia \\ Vancouver, British Columbia, Canada V6T 1 Z3 \\ ${ }^{5}$ Corresponding author: Tel, 82-31-219-4558; \\ Fax, 82-31-216-6381; E-mail, yblee@ @ajou.ac.kr
}

Accepted 19 November 2007

Abbreviations: ABC, ATP binding cassette; $A \beta, \beta$ amyloid peptide; AD, Alzheimer's disease; $\alpha$-Bgt, $\alpha$-bungarotoxin; CREB, cAMP response element binding protein; DCF-DA, dihydrodichlorofluorescein diacetate; $f A \beta$, fibrillar $A \beta$; Mec, mecamylamine; $n A C h R$, nicotinic acetylcholine receptors; OATP, oxidized ATP; PI3-K, PI3 kinase; PPADS, pyridoxal-phosphate-6-azophenyl-2',4'-disulfonate; $\mathrm{P} 2 \mathrm{X}_{7} \mathrm{R}, \mathrm{P} 2 \mathrm{X}_{7}$ receptor; ROS, reactive oxygen species

\footnotetext{
Abstract

Recent studies have reported that the "cholinergic anti-inflammatory pathway" regulates peripheral inflammatory responses via $\alpha 7$ nicotinic acetylcholine receptors ( $\alpha 7 \mathrm{nAChRs})$ and that acetylcholine and nicotine regulate the expression of proinflammatory mediators such as TNF- $\alpha$ and prostaglandin $E_{2}$ in microglial cultures. In a previous study we showed that ATP released by $\beta$-amyloid-stimulated microglia induced reactive oxygen species (ROS) production, in a process involving the $P 2 X_{7}$ receptor $\left(P 2 X_{7} R\right)$, in an autocrine fashion. These observations led us to investigate whether stimulation by nicotine could regulate fibrillar $\beta$ amyloid peptide (1-42) (fA $\beta_{1-42}$ )-induced ROS production by modulating ATP efflux-mediated $\mathrm{Ca}^{2+}$ influx through $P 2 X_{7} R$. Nicotine inhibited ROS generation in fA $\beta_{1-42-}$ stimulated microglial cells, and this inhibition was blocked by mecamylamine, a non-selective nAChR antagonist, and $\alpha$-bungarotoxin, a selective $\alpha 7$ nAChR antagonist. Nicotine inhibited NADPH oxidase
}

activation and completely blocked $\mathrm{Ca}^{2+}$ influx in fA $\beta_{1-42}$-stimulated microglia. Moreover, ATP release from $f A \beta_{1-42}$-stimulated microglia was significantly suppressed by nicotine treatment. In contrast, nicotine did not inhibit 2',3'-0-(4-benzoyl)-benzoyl ATP (BzATP)-induced $\mathrm{Ca}^{2+}$ influx, but inhibited ROS generation in BzATP-stimulated microglia, indicating an inhibitory effect of nicotine on a signaling process downstream of $P_{2} X_{7} R$. Taken together, these results suggest that the inhibitory effect of nicotine on ROS production in fA $\beta_{1-42}$-stimulated microglia is mediated by indirect blockage of ATP release and by directly altering the signaling process downstream from $P 2 X_{7} R$.

Keywords: acetylcholine; adenosine triphosphate; amyloid $\beta$-protein; microglia; NADPH oxidase; nicotine; reactive oxygen species; receptors, nicotinic; purinoceptor P2Z

\section{Introduction}

The neuropathological hallmarks of Alzheimer's disease (AD) include extracellular deposition of the beta amyloid peptide $(A \beta)$ in the form of senile plaques and the appearance of intracellular neurofibrillary tangles composed of hyperphosphorylated tau (Akiyama et al., 2000). Another neuropathological feature of $A D$ is the loss of both cholinergic neurons (Davies and Maloney, 1976; McGeer et al., 1984; Muir, 1997) and nicotinic acetylcholine receptors (nAChRs) (Burghaus et al., 2000; Mousavi et al., 2003) in the basal forebrain, which contributes to cognitive dysfunction. The $\mathrm{nAChR}$ is a ligand-gated ion channel consisting of five subunits with eight different $\alpha(\alpha 2-\alpha 9)$ subunits and three different $\beta$ ( $\beta 2-\beta 4)$ components (Gotti and Clementi, 2004). Of these nAChRs, $\alpha 7$ and $\alpha 4 \beta 2$ are the most abundant subunits in the brain (Buisson and Bertrand, 2002). The administration of nAChR agonists in aging animals and humans induced cognitive improvement (Newhouse et al., 1997; Terry and Buccafuso, 2003) and prevented neuronal death induced by $A \beta$ (O'Neill et al., 2002).

A recent study suggests that $\alpha 7$ nAChRs, expressed in peripheral macrophages, are essential for operation of the so-called "cholinergic anti- 
inflammatory pathway" that regulates systemic inflammatory responses in the peripheral nervous system (Wang et al., 2003). Recent studies have revealed that the $\alpha 7 \mathrm{nAChRs}$ are expressed in murine microglia in addition to neurons and peripheral macrophages, and are involved in the suppression of neuroinflammation (Shytle et al., 2004; De Simone et al., 2005). Such unique receptors should play an important role in neuroprotection, because of the activation of $\alpha 7 \mathrm{nAChRs}$ in capable of modulating the activity of microglia, changing the microglial cell from an overactive inflammatory cell to a protective cell type (Suzuki et al., 2006).

One of the mechanisms explaining $A \beta$ neurotoxicity is that microglia-mediated oxidative stress, via NADPH oxidase activation, plays a critical role in the pathogenesis of $A D$. Fibrillar $A \beta$ (fA $\beta$ ) stimulates reactive oxygen species (ROS) production from cultured microglial cells via activation of NADPH oxidase (Bianca et al., 1999). In addition, $\mathrm{fA} \beta$ mediated neurotoxicity in mixed neuron-microglia cultures by causing the production of ROS (Qin et al., 2002). Furthermore, NADPH oxidase activation has been identified in $A D$ brains (Shimohama et al., 2000). Our previous study demonstrated that one of the mechanisms of ROS production in $A \beta$-stimulated microglia involved

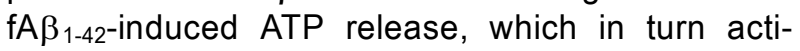
vated NADPH oxidase in a process involving the $P 2 X_{7}$ receptor $\left(P 2 X_{7} R\right)$, in an autocrine manner (Kim et al., 2007). Therefore, to determine whether the activation of $\mathrm{nAChRs}$ affects ROS generation in $f A \beta_{1-42}$-stimulated microglia, we examined the inhibitory effects of nicotine on ROS production and NADPH oxidase activation in such cells, and then investigated the effects of nicotine on ATP efflux and $\mathrm{Ca}^{2+}$ influx.

\section{Materials and Methods}

\section{Reagents}

Medium and supplement for cell culture were purchased from JBI (Daegu, Korea). Chemicals were purchased from the following companies: Amyloid$\beta_{1-42}\left(A \beta_{1-42}\right)$ was purchased from the American Peptide (Sunnyvale, CA). Mecamylamine hydrochloride, $\alpha$-bungarotoxin, pyridoxal-phosphate-6azophenyl-2',4'-disulfonate (PPADS), adenosine 5'triphosphate 2',3'-acylic dialcohol (oxidized ATP; oATP), apyrase (an ATP-hydrolyzing enzyme), 2', 7'-dihydrodichlorofluorescein diacetate (DCF-DA), pluronic F-127, DNase I, an ATP bioluminescence assay kit, and a protease inhibitor mixture, were all purchased from Sigma (St. Louis, MO). Nicotine ([S]-3-[1-methyl-2-pyrrolindinyl] pyridine, di- $d$-Tar- trate) was from Calbiochem (San Diego, CA), Fluo-3/AM was from Molecular probes (Eugene, OR). The anti-mouse and anti-rabbit HRP-conjugated secondary anti-bodies were purchased from Amersham Pharmacia (Buckinghamshire, UK). The polyclonal antibody against $\mathrm{p} 47^{\text {phox }}, \mathrm{P} 67^{\text {phox }}$, and Rac 1 was provided by BD Biosciences (San Diego, CA).

\section{Microglial cell culture}

Microglial cultures were prepared from the brains of 3 day-old Sprague-Dawley rats as described previously (Kim et al., 2002). Briefly, whole brains were dissected into small cubes, incubated in D-PBS containing $0.1 \%$ trypsin and $40 \mu \mathrm{g} / \mathrm{ml}$ DNase I for $15 \mathrm{~min}$ at $37^{\circ} \mathrm{C}$, and dissociated into single cells by gentle pipetting. Dissociated cells were suspended in DMEM (JBI) containing 5\% horse serum, $5 \mathrm{mg} / \mathrm{ml}$ glucose, $100 \mathrm{U} / \mathrm{ml}$ penicillin and $100 \mu \mathrm{g} / \mathrm{ml}$ streptomycin, and plated on polyD-lysine-coated T-75 culture flasks, and incubated at $37^{\circ} \mathrm{C}$ in incubator with $5 \% \mathrm{CO}_{2} / 95 \%$ air atmosphere. After 2-4 weeks of growth in flasks, microglia floating in the medium were collected and grown in separate 6-, 96-well plates or on coverslips.

\section{Measurement of intracellular ROS}

Intracellular ROS levels were measured using the fluorescent dye, dihydrodichlorofluorescein diacetate (DCF-DA), which is readily converted to a fluorescent product in the presence of ROS in cells. In brief, cells were preincubated with nicotine (1-100 $\mu \mathrm{M})$ for $30 \mathrm{~min}$ in the presence or absence of mecamylamine $(10 \mu \mathrm{M}), \alpha$-bungarotoxin (10 $\mathrm{nM})$, and then treated with $0.5 \mu \mathrm{M} f A \beta_{1-42}$ or 300 $\mu \mathrm{M}$ BzATP. fA $\beta_{1-42}$-stimulated cells were incubated with $10 \mu \mathrm{M}$ DCF-DA in HBSS (145 mM NaCl, 2.5 $\mathrm{mM} \mathrm{KCl}, 1.8 \mathrm{mM} \mathrm{MgCl}, 1 \mathrm{mM} \mathrm{CaCl}, 10 \mathrm{mM}$ D-glucose and 20 mM HEPES; pH 7.4) for $30 \mathrm{~min}$. The cells were then washed extensively with D-PBS to remove extracellular DCF-DA, and fluorescence images were taken using an IX71 confocal laser scanning microscope (Olympus; Tokyo, Japan).

\section{Western blot analysis}

Microglial cells treated with $f A \beta_{1-42}$ were lysed with lysis buffer (10 mM Na $2 \mathrm{HPO}_{4}, 150 \mathrm{mM} \mathrm{NaCl}, 0.5 \%$ sodium deoxycholate, $0.1 \%$ SDS, and $1 \%$ NP 40 ; $\mathrm{pH}$ 7.5). Lysates were centrifuged at $13,000 \times g$ for $10 \mathrm{~min}$ at $4^{\circ} \mathrm{C}$ and supernatants were collected. An aliquot of each sample containing $20 \mu \mathrm{g}$ total protein was loaded onto a $10 \%$ acrylamide gel, and then transferred to a PVDF membrane. The 
blots were incubated with blocking buffer [5\% skim milk in TBST $(20 \mathrm{mM}$ Tris- $\mathrm{HCl}, 500 \mathrm{mM} \mathrm{NaCl}$, $0.05 \%$ Tween 20, pH7.5)] at room temperature for $1 \mathrm{~h}$, and incubated with primary antibody overnight at $4^{\circ} \mathrm{C}$. The bands were recognized by HRP conjugated anti-rabbit secondary antibody (1: $1,000)$. For detecting the translocation of NADPH oxidase components, primary monoclonal antibodies against the $\mathrm{p} 47^{\text {phox }}(1: 500), \mathrm{p} 67^{\text {phox }}(1$ : $500)$, Rac 1 (1:500), and HRP conjugated antimouse secondary antibody $(1: 1,000)$ were used.

\section{Cell fractionation}

Microglial cells were harvested and resuspended in a cold hypotonic solution $(0.25 \mathrm{M}$ sucrose, 10 $\mathrm{mM}$ Tris- $\mathrm{HCl}$, and $5 \mathrm{mM} \mathrm{MgCl} ; \mathrm{pH} 7.4$ ) including a protease inhibitor mixture, and centrifuged at 600 $\times g$ for $10 \mathrm{~min}$. The supernatant was ultracentrifuged at $100,000 \times g$ for $1.5 \mathrm{~h}$ at $4^{\circ} \mathrm{C}$. The resulting supernatant was removed and saved as the cytosolic fraction, and the membrane pellet was resuspended in hypotonic solution containing 1\% Triton X-100. Samples were analyzed by Western blotting using antibodies against the NADPH oxidase components $\mathrm{p} 47^{\text {phox }}, \mathrm{p} 67^{\text {phox }}$, and Rac 1 as described above.

\section{Measurement of intracellular calcium}

Intracellular $\mathrm{Ca}^{2+}$ concentration was monitored by loading cells with the fluorescent $\mathrm{Ca}^{2+}$ indicator Fluo-3/AM, convertible to Fluo-3 in the presence of $\mathrm{Ca}^{2+}$. Cultured microglia plated onto poly-D-lysinecoated $25 \mathrm{~mm}$ glass coverslips were incubated with $2 \mu \mathrm{M}$ of the acetoxymethyl ester of Fluo-3 (Fluo-3/AM) and $0.02 \%$ pluronic F-127 in HBSS for $30 \mathrm{~min}$ at $37^{\circ} \mathrm{C}$, and then washed with HBSS. Fluo-3-loaded cells were placed in a perfusion chamber mounted on the stage of a confocal laser-scanning microscope and stimulated with 0.5 $\mu \mathrm{M} f \mathrm{~A} \beta_{1-42}$. To measure the intracellular calcium concentration, a confocal laser-scanning microscope (IX71, Olympus) equipped with an Argon/ Keron laser (15 mW; Coherent, Santa Clara, CA) was used. Fluo-3 was excited by the $488 \mathrm{~nm}$ line of an argon laser and the fluorescence was measured at an emission wavelength above $510 \mathrm{~nm}$.

\section{ATP efflux measurement}

Microglial cells $\left(3 \times 10^{4}\right.$ cells/well) were plated in 96-well, and preincubated with nicotine $(1-100 \mu \mathrm{M})$ for $30 \mathrm{~min}$, and then treated with $0.5 \mu \mathrm{M}$ fA $\beta_{1-42}$ for $1 \mathrm{~h}$. At the end of this incubation, the supernatant fluids of individual wells was transferred into sterile tubes and heated at $95^{\circ} \mathrm{C}$ for $3 \mathrm{~min}$. Extracellular
ATP in the supernatants was immediately measured by luminometer (TD2020, Turner Designs, Sunnyvale, CA), using a luciferase-luciferin assay (ATP bioluminescent assay kit from Sigma) following the instructions of the manufacturer.

\section{Statistical analysis}

All statistical comparisons in this study were done using one-way ANOVA with Tukey-Kramer multiple comparisons test and data were expressed as mean \pm SEM. A value of $P<0.05$ was considered statistically significant.

\section{Results}

\section{Nicotine inhibits $f A \beta_{1-42}$-induced ROS production in microglia}

We examined the effects of nicotine on ROS production in $f A \beta_{1-42}$-stimulated microglia by measuring fluorescence signals from DCF-DA. Microglial cells were pre-treated with $1 \mu \mathrm{M}, 10 \mu \mathrm{M}$, or $100 \mu \mathrm{M}$ nicotine for $30 \mathrm{~min}$ and then stimulated with $0.5 \mu \mathrm{M} f A \beta_{1-42}$ for $2 \mathrm{~h}$. Nicotine significantly decreased DCF fluorescence signals, in a dosedependent manner (Figure 1). These results indicated that neuroprotective functions of nicotine might be mediated by suppressing $f A \beta_{1-42}$-induced ROS production in microglia.

\section{Nicotine modulates ROS production via activation of nAChRs}

To determine whether $n A C h R s$ are involved in the nicotine inhibition of ROS production in microglia, we examined the effects of mecamylamine, a nonselective $n A C h R$ antagonist, and $\alpha$-bungarotoxin, a selective $\alpha 7 \mathrm{nAChR}$ antagonist on the nicotineinduced decrease in ROS production. Nicotine treatment caused a marked reduction in $f A \beta_{1-42^{-}}$ induced ROS production. On the other hand, treatment with mecamylamine $(10 \mu \mathrm{M})$ or $\alpha$-bungarotoxin $(10 \mathrm{nM})$ significantly eliminated this inhibitory activity of nicotine (Figure 2).

\section{fA $\beta_{1-42}$-induced NADPH oxidase activation is inhibited by nicotine}

Because nicotine showed potent negative effects on ROS production, we sought to determine whether nicotine might inhibit NADPH oxidase activation by preventing the translocation of the NADPH oxidase cytoplasmic subunits $\mathrm{p} 47^{\text {phox }}, \mathrm{p} 67^{\text {phox }}$, and Rac 1 from the cytosol to the cell membrane after $f A \beta_{1-42}$ stimulation. Following $f A \beta_{1-42}$ treatment, the 
A

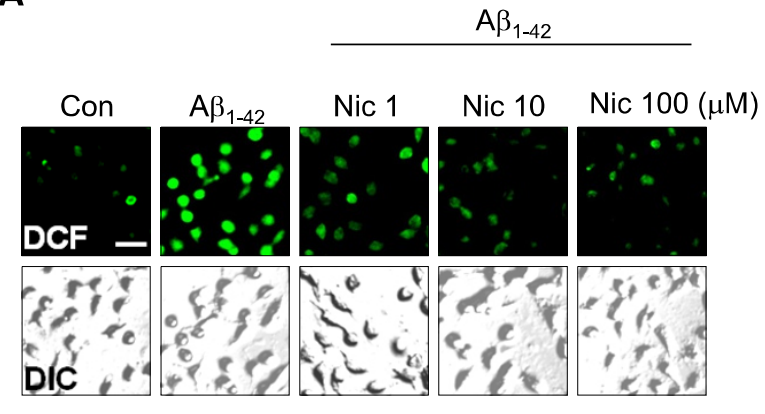

B

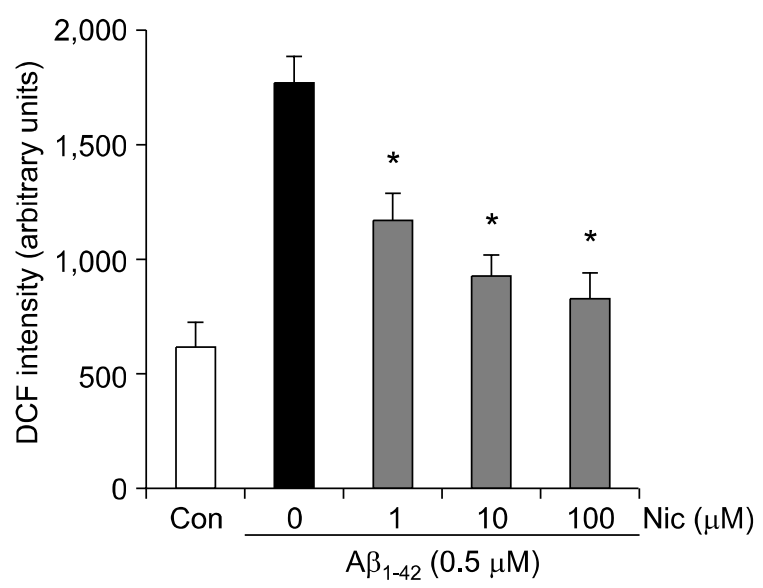

Figure 1. Effects of nicotine on reactive oxygen species production in fA $\beta_{1-42}$-stimulated microglia. (A) Primary rat microglia were plated onto coverslips $\left(3 \times 10^{4}\right.$ cells/coverslip), and then microglia were pretreated with nicotine for 30 min and stimulated with $f A \beta_{1-42}(0.5 \mu \mathrm{M})$ for $2 \mathrm{~h}$. The intracellular ROS production in microglial cells was determinded using $10 \mu \mathrm{M}$ DCF as described in Materials and Methods. (B) DCF intensities of cells were counted using Imagegage 4.0 (Fujifilm). Fluorescence (DCF) images and differential interference contrast (DIC) images were taken using an IX71 confocal microscope (Olympus). Values are mean \pm SEM of $40-50$ cells. ${ }^{*} P<0.01$ compared with $A \beta_{1-42}$ alone. Scale bar, $20 \mu \mathrm{m}$.

amounts of $\mathrm{p} 47^{\text {phox }}, \mathrm{p} 67^{\text {phox }}$, and Rac 1 in the membrane fraction increased, but the translocation of the cytosolic factors $\mathrm{p} 47^{\text {phox }}, \mathrm{p} 67^{\text {phox }}$, and Rac 1 to the plasma membrane was prevented by nicotine treatment $(10 \mu \mathrm{M})$ (Figure 3 ). These results indicate that nicotine reduced $f A \beta_{1-42}$-induced ROS production through the inhibition of NADPH oxidase activation.

\section{Nicotine inhibits $f A \beta_{1-42}$-induced ROS production in microglia by inhibition of ATP release from microglia, and not by blockade of $P 2 X_{7} R$}

Our previous study demonstrated that $f A \beta_{1-42^{-}}$ stimulated ROS generation in microglial cells is regulated by ATP release-mediated $\mathrm{Ca}^{2+}$ influx

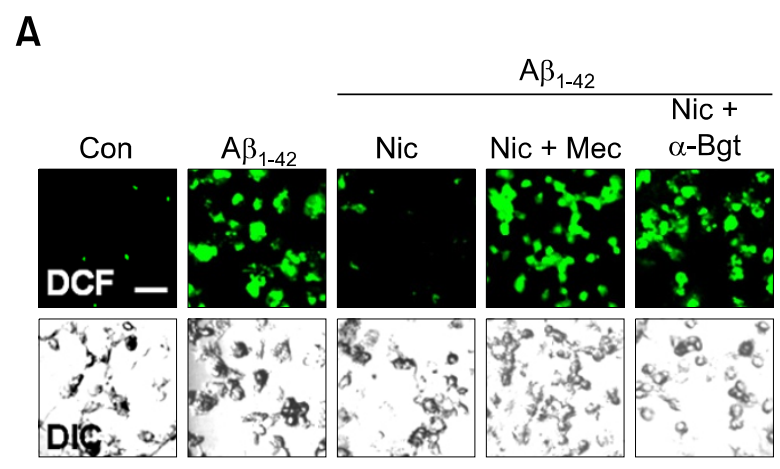

B

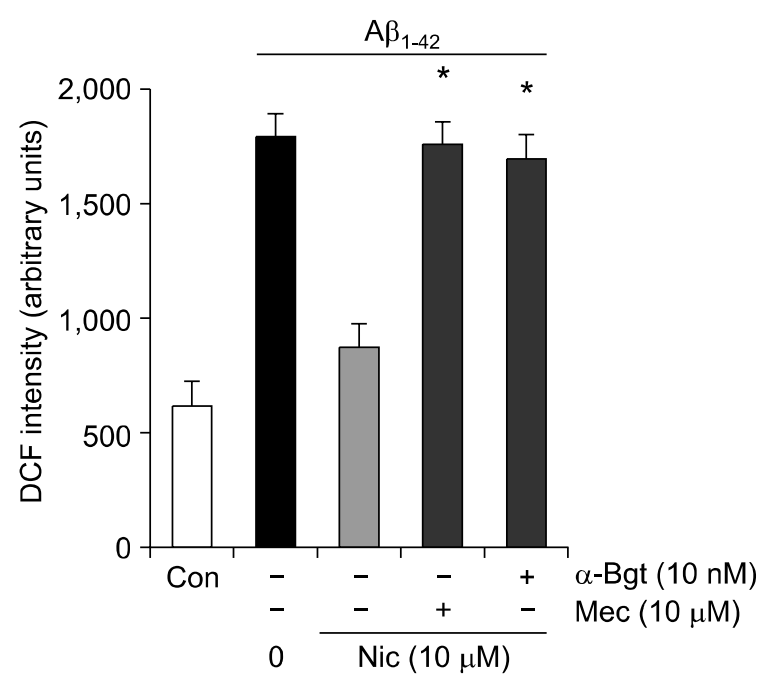

Figure 2. Effects of $n A C h R s$ antagonists on $f A \beta_{1-42}$-induced ROS production from nicotine-treated microglia. (A) The cells were preincubated with nicotine $(10 \mu \mathrm{M})$ for $30 \mathrm{~min}$ in the presence or absence of $10 \mu \mathrm{M}$ mecamylamine $(\mathrm{Mec})$ or $10 \mathrm{nM} \alpha$-bungarotoxin $(\alpha$-Bgt), and then treated with $0.5 \mu \mathrm{M}$ fA $\beta_{1-42}$ for $2 \mathrm{~h}$. The intracellular ROS production in microglial cells was determined using $10 \mu \mathrm{M}$ DCF as described in Materials and Methods. (B) DCF intensities of cells were counted using Imagegage 4.0 (Fujifilm). Fluorescence (DCF) images and differential interference contrast (DIC) images were taken using an IX71 confocal microscope (Olympus). Values are mean \pm SEM of $40-50$ cells. ${ }^{*} P<0.01$ compared with $A \beta_{1-42}$ plus nicotine. Scale bar, $20 \mu \mathrm{m}$.

through $\mathrm{P} 2 \mathrm{X}_{7} \mathrm{R}$, in an autocrine manner (Kim et al., 2007). Therefore, we investigated the effects of nicotine on ATP efflux and $\mathrm{Ca}^{2+}$ influx in $\mathrm{fA} \beta_{1-42^{-}}$ stimulated microglia. Surprisingly, pretreatment of microglia with nicotine $(10 \mu \mathrm{M})$ reduced $f A \beta_{1-42^{-}}$ induced $\mathrm{Ca}^{2+}$ influx to baseline levels in consistent with our previous study which showed the blockade of $\mathrm{Ca}^{2+}$ influx by pretreatment with apyrase (an ATP-hydrolyzing enzyme; $5 \mathrm{U} / \mathrm{ml})$, or oATP (a $\mathrm{P} 2 \mathrm{X}_{7} \mathrm{R}$-specific antagonist; $\left.100 \mu \mathrm{M}\right)$ in $\mathrm{fA} \beta_{1-42^{-}}$ stimulated microglia (Figure 4A). Moreover, ATP release from $f A \beta_{1-42}$-stimulated microglia was significantly suppressed by nicotine treatment (Figure $4 B)$. At this point, because a previous study had 
A

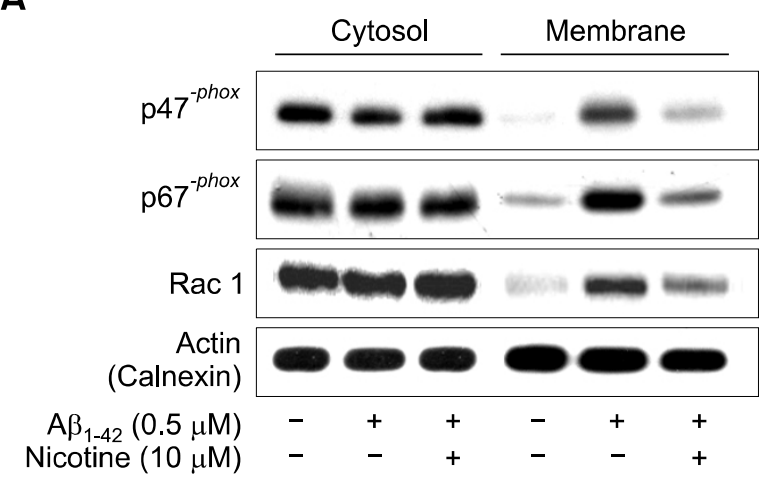

B

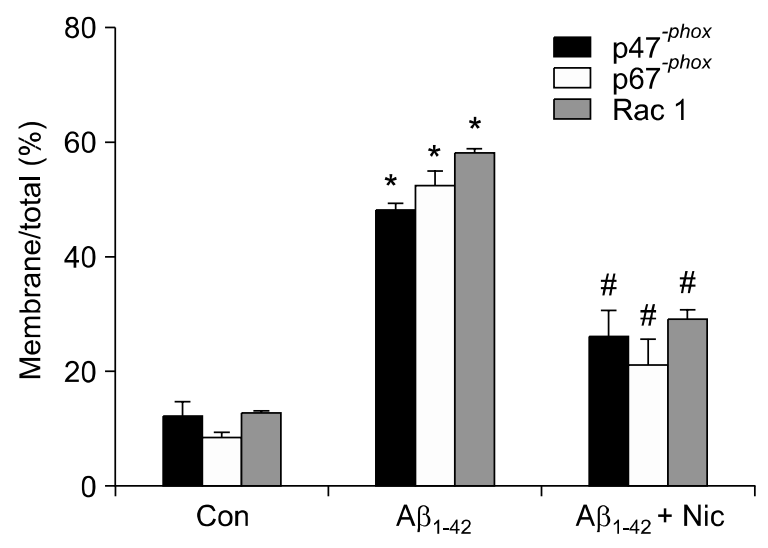

Figure 3. Nicotine inhibits $f A \beta_{1-42}$-induced NADPH oxidase activation. NADPH oxidase was activated by $f A \beta_{1-42}$, as evidenced by the translocation of the $\mathrm{p} 47^{\text {phox }}, \mathrm{p} 67^{\text {phox }}$, Rac 1 subunits from the cytosol to the membrane; this translocation was inhibited by nicotine treatment. (A) The cells were treated with $10 \mu \mathrm{M}$ nicotine for $30 \mathrm{~min}$ and stimulated with $0.5 \mu \mathrm{M} \mathrm{fA} \beta_{1-42}$ for $90 \mathrm{~min}$. Fractionated proteins were analyzed by SDS-PAGE and subjected to immunoblotting with anti-p47 $7^{\text {phox }}$, anti-p67 $7^{\text {phox }}$, anti-Rac 1 antibody. The blots were reprobed with antibodies against the calnexin membrane protein as loading controls to exhibit fractionation efficiency. (B) The histogram shows quantitation of $p 67^{\text {phox }}$, $\mathrm{p} 47^{\text {phox }}$, Rac 1 levels expressed as the ratio of membrane fraction to total. The results represent the mean \pm SEM of four to five separate experiments. ${ }^{*} P<0.01$ compared with control, ${ }^{\sharp} P<0.01$ compared with $A \beta_{1-42}$ alone.

reported superoxide generation after $\mathrm{Ca}^{2+}$ influx through $\mathrm{P} 2 \mathrm{X}_{7} \mathrm{R}$ in microglia (Parvathenani et al., 2003), we investigated the effects of nicotine on the activation of $P 2 X_{7} R$ by examining the effects of the drug on $\mathrm{Ca}^{2+}$ influx in BzATP-stimulated microglia. Pretreatment of microglia with nicotine (10 $\mu \mathrm{M})$ did not inhibit BzATP-induced $\mathrm{Ca}^{2+}$ influx (Figure 4C), but inhibited BzATP-induced ROS generation (Figure 4D), indicating that an inhibitory effect of nicotine lies downstream of signaling initiated from $P 2 X_{7} R$. Taken together, these results suggest that the inhibitory effects of nicotine on fA $\beta_{1-42}$-induced ROS production are mediated by inhibition of ATP efflux from microglia, resulting in blockade of $\mathrm{Ca}^{2+}$ influx, and by prevention of $\mathrm{P} 2 \mathrm{X}_{7} \mathrm{R}$ intracellular signaling.

\section{Discussion}

The present study demonstrates the neuroprotective effects of nicotine against $f A \beta_{1-42}$-induced ROS production in rat microglial cultures. First, nicotine inhibits $f A \beta_{1-42}$-induced ROS production via activation of $n A C h R s$ and activation of $f A \beta_{1-42-}$ induced microglial NADPH oxidase. Second, nicotine inhibits $f A \beta_{1-42}$-induced ROS production by blocking the $\mathrm{Ca}^{2+}$ influx that follows inhibition of ATP efflux, and by prevention of $P 2 X_{7} R$ downstream signaling.

$f A \beta_{1-42}$ has a direct toxic effect on neurons, but the accumulation of activated microglia at sites of $f A \beta_{1-42}$ deposits in $A D$ indicates that activated microglia may also contribute to the progression of the disease (Akiyama et al., 2000). Recently, several lines of evidence have shown that oxidative stress plays an important role in inflammationmediated neurodegeneration in $A D$ (de la Monte and Wands, 2006; Sultana et al., 2006). A $\beta$ stimulates ROS generation from cultured microglial cells via activation of NADPH oxidase (Bianca et al., 1999) and mediates neurotoxicity by stimulating production of ROS in mixed neuron-microglia cultures (Qin et al., 2002). Besides A $\beta$ neurotoxicity, another feature of $A D$ is the loss of cholinergic projections and decline of nAChRs from the early stage of AD (Oddo and LaFerla, 2006). In this regard, recent studies have reported the existence of a cholinergic control of microglial activation by showing that nicotine reduced LPSinduced production of TNF- $\alpha$ and IL-18, indicating that nicotine has immunosuppressive effects (Shytle et al., 2004; De Simone et al., 2005; Suzuki et al., 2006; Takahashi et al., 2006). On the other hand, nicotine treatment significantly increased the expression of COX-2 and the synthesis of $\mathrm{PGE}_{2}$ in LPS-stimulated microglia, and even enhanced TNF- $\alpha$ production in BzATP-stimulated microglia, suggesting a neuroprotective effect of nicotine at low concentration (De Simone et al., 2005). In this paper we expand the neuroprotective role of nicotine by showing that nicotine inhibits $f A \beta_{1-42}$-induced ROS production and NADPH oxidase activation in microglia. In line with our results, a recent study reported a neuroprotective effect of nicotine on dopaminergic neurons using LPS-induced in vitro and in vivo inflammation models (Park et al., 2007).

Our previous study showed that ROS generation in $f A \beta_{1-42}$-stimulated microglia is mediated by ATP 
A

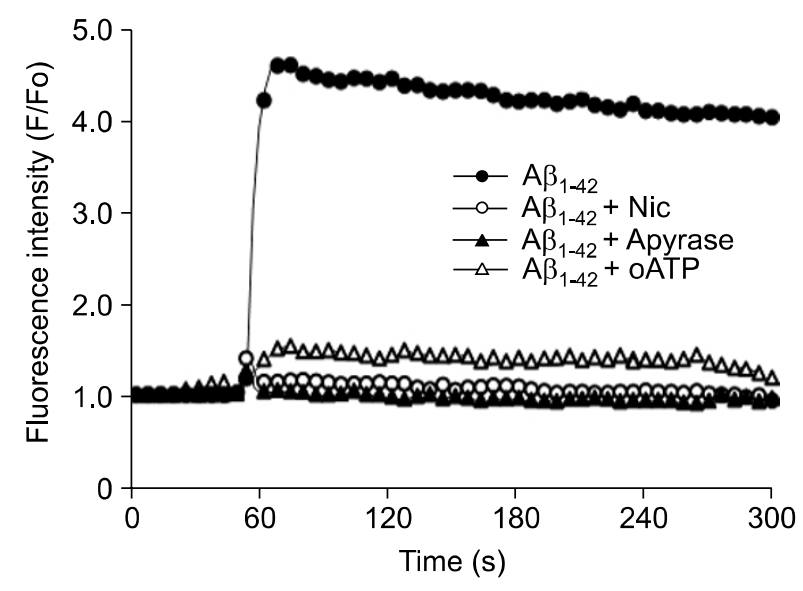

C

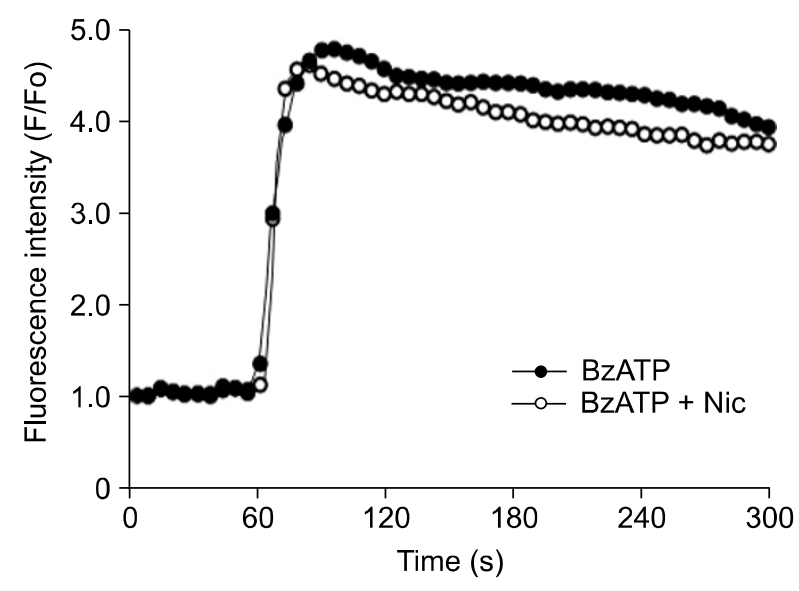

B

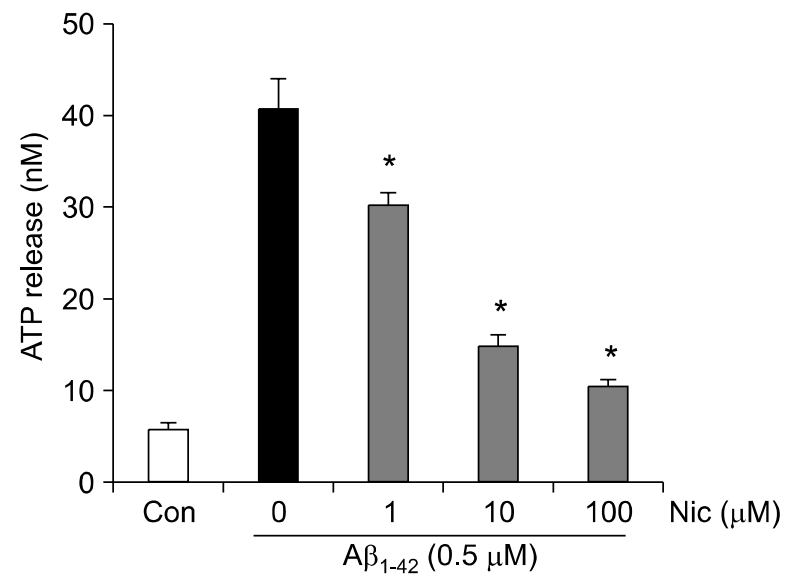

D

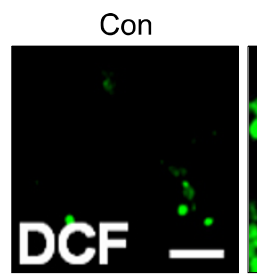

BzATP
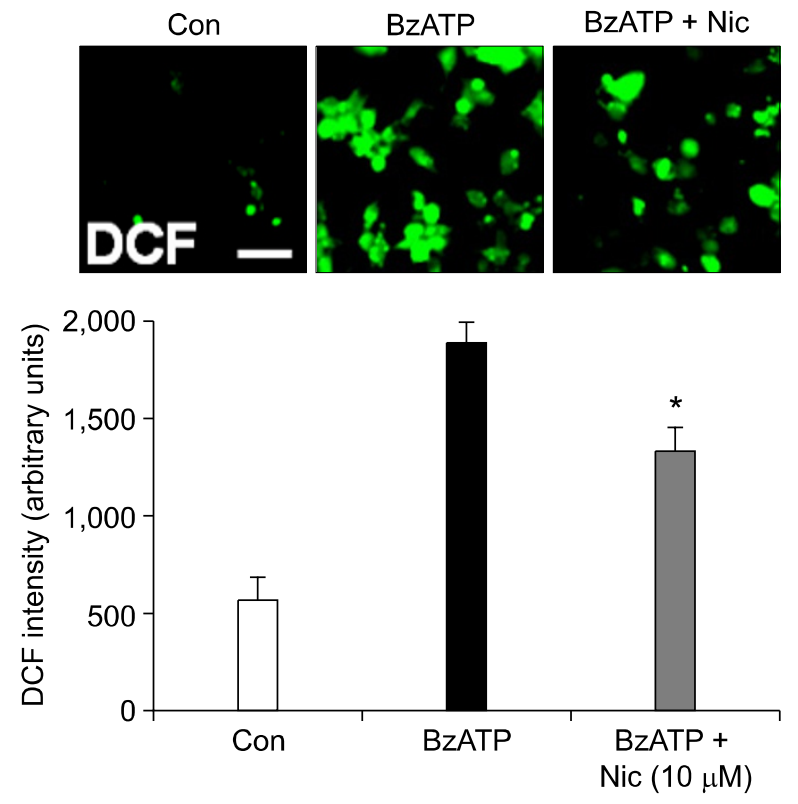

Figure 4. Effects of nicotine on $\mathrm{Ca}^{2+}$ influx in $\mathrm{fA} \beta_{1-42}$ - or BzATP-stimulated microglia and ATP efflux in $\mathrm{fA} \beta_{1-42}$-stimulated microglia. Microglial cells were plated onto coverslips $\left(3 \times 10^{4}\right.$ cells/coverslip), and pretreated with nicotine $(10 \mu \mathrm{M})(\mathrm{A}-\mathrm{D})$, apyrase $(5 \mathrm{U} / \mathrm{ml})$, or oATP $(100 \mu \mathrm{M})$ for $30 \mathrm{~min}(\mathrm{~A})$, and then treated with $0.5 \mu \mathrm{M} \mathrm{fA} \beta_{1-42}$ ( $A$ and $B$ ) or $300 \mu \mathrm{M}$ BzATP ( $C$ and $D$ ). ( $A$ and $C$ ) Intracellular $\mathrm{Ca}^{2+}$ concentration was measured by Fluo-3 as described in Materials and Methods, and represented by the ratio between the fluorescence intensity after treatment $(F)$ and fluorescence in the resting state $\left(F_{0}\right)$. (B) Microglial cells $\left(3 \times 10^{4}\right.$ cells/well) were plated into 96 well plate, and pretreated with nicotine $(10 \mu \mathrm{M})$ for 30 min, and then treated with $0.5 \mu \mathrm{M}$ $f A \beta_{1-42}$. ATP concentrations in the culture supernatants were determined at $1 \mathrm{~h}$ after $\mathrm{fA} \beta_{1-42}$ stimulation. Values are mean $\pm \mathrm{SEM}$ of triplicate samples. ${ }^{*} P<0.01$ compared with $A \beta_{1-42}$. (D) Microglial cells were plated onto coverslips $\left(3 \times 10^{4}\right.$ cells/coverslip), and pretreated with nicotine $(10 \mu \mathrm{M})$ for 30 min, and then treated with $300 \mu \mathrm{M}$ BzATP. Intracellular ROS levels were assayed $2 \mathrm{~h}$ after BzATP stimulation using $10 \mu \mathrm{M}$ DCF. Fluorescence (DCF) images were taken using an IX71 confocal microscope (Olympus). Scale bar, $20 \mu \mathrm{m}$. DCF intensities of cells were counted using Imagegage 4.0 (Fujifilm). Values are mean \pm SEM of $40-50$ cells. ${ }^{*} P<0.01$ compared with BzATP alone.

release and subsequent $\mathrm{Ca}^{2+}$ influx, in a process involving the activation of $P 2 X_{7} R$, in an autocrine manner (Kim et al., 2007). Interestingly, the pre- sent study demonstrated that inhibitory effects of nicotine on $f A \beta_{1-42}$-induced ROS production are mediated by decreasing $\mathrm{Ca}^{2+}$ influx to a basal level 
through inhibition of ATP release from microglia. On the other hand, pretreatment with nicotine did not inhibit BzATP-elicited $\mathrm{Ca}^{2+}$ influx. These results indicate that blockade of $\mathrm{fA} \beta_{1-42}$-elicited $\mathrm{Ca}^{2+}$ influx by nicotine treatment is mediated by preventing ATP release from microglia, and not by either interference with ATP binding to $P 2 X_{7} R$ or by decreasing the activity of this channel. Recently, it has been recognized that ATP can be released from LPS- or glutamate-stimulated microglial cells (Ferrari et al., 1997; Seo et al., 2004; Liu et al., 2006), and ATP efflux from either astrocytes or microglia occurred via ATP binding cassette (ABC) proteins (Ballerini et al., 2002). Future work on identifying the mechanisms involved in nicotinemediated inhibition of ATP release will provide a better understanding of the role of nicotine under the pathological conditions of AD.

Besides blockade of $\mathrm{Ca}^{2+}$ influx by inhibition of ATP efflux, nicotine-induced suppression of ROS production in $f A \beta_{1-42}$-stimulated microglia seems to also involve interference with $P 2 X_{7} R$ downstream signaling. Our present results showed that pretreatment of microglia with nicotine did not inhibit BzATP-induced $\mathrm{Ca}^{2+}$ influx but did inhibit BzATP-induced ROS generation. It has been shown that p38 MAPK and PI3 kinase (PI3-K) play key roles in the production of ROS in BzATP-stimulated microglia (Parvathenani et al., 2003). However, a recent study reported that nicotine did not affect the activation of p38 MAPK in BzATP-stimulated microglia (Suzuki et al., 2006), and it remains unclear whether nicotine inhibits PI3-K in BzATPstimulated microglia.

In conclusion, our study provides evidence for the first time that nicotine can downregulate ROS production in $f A \beta_{1-42}$-stimulated microglia by inhibition of both ATP release and $P 2 X_{7} R$ signaling. The finding that nicotine prevents ROS production in microglia provides evidence for molecular links between $A \beta$, cholinergic dysfunction, and cognitive impairments, during the progress of $A D$.

\section{Acknowledgment}

This work was supported by the Korea Science and Engineering Foundation (KOSEF) through the Brain Disease Research Center at Ajou University, and the Korea Health 21 R\&D Project, Ministry of Health and Welfare, Republic of Korea; Grant 03-PJ1-PG10-21300-0006.

\section{References}

Akiyama H, Barger S, Barnum S, Bradt B, Bauer J, Cole GM, Cooper NR, Eikelenboom P, Emmerling M, Fiebich BL. Inflammation and Alzheimer's disease. Neurobiol Aging

\section{0;21:383-421}

Ballerini P, Di lorio P, Ciccarelli R, Nargi E, D'Alimonte I, Traversa U, Rathbone MP, Caciagli F. Glial cells express multiple ATP binding cassette proteins which are involved in ATP release. Neuroreport 2002;13:1789-92

Bianca VD, Dusi S, Bianchini E, Dal Pra I, Rossi F. $\beta$-amyloid activates the $0-2$ forming NADPH oxidase in microglia, monocytes, and neutrophils. A possible inflammatory mechanism of neuronal damage in Alzheimer's disease. J Biol Chem 1999;274:15493-9

Buisson B, Bertrand D. Nicotine addiction: the possible role of functional upregulation. Trends Pharmacol Sci 2002; 23:130-6

Burghaus L, Schutz U, Krempel U, de Vos RA, Jansen Steur EN, Wevers A, Lindstrom J, Schroder H. Quantitative assessment of nicotinic acetylcholine receptor proteins in the cerebral cortex of Alzheimer patients. Brain Res Mol Brain Res 2000;76:385-8

Davies P, Maloney AJ. Selective loss of central cholinergic neurons in Alzheimer's disease. Lancet 1976;2:1403

de la Monte SM, Wands JR. Molecular indices of oxidative stress and mitochondrial dysfunction occur early and often progress with severity of Alzheimer's disease. J Alzheimers Dis 2006;9:167-81

De Simone R, Ajmone-Cat MA, Carnevale D, Minghetti L. Activation of $\alpha 7$ nicotinic acetylcholine receptor by nicotine selectively up-regulates cyclooxygenase-2 and prostaglandin E2 in rat microglial cultures. J Neuroinflammation 2005;2:4-13

Ferrari D, Chiozzi P, Falzoni S, Hanau S, Di Virgilio F. Purinergic modulation of interleukin-1 $\beta$ release from microglial cells stimulated with bacterial endotoxin. J Exp Med 1997;185:579-82

Gotti C, Clementi F. Neuronal nicotinic receptors: from structure to pathology. Prog Neurobiol 2004;74:363-96

Kim KY, Kim MY, Choi HS, Jin BK, Kim SU, Lee YB. Thrombin induces IL-10 production in microglia as a negative feedback regulator of TNF- $\alpha$ release. Neuroreport 2002;13:849-52

Kim SY, Moon JH, Lee HG, Kim SU, Lee YB. ATP released from $\beta$-amyloid-stimulated microglia induces reactive oxygen species production in an autocrine fashion. Exp Mol Med 2007;39:820-7

Liu GJ, Kalous A, Werry EL, Bennett MR. Purine release from spinal cord microglia after elevation of calcium by glutamate. Mol Pharmacol 2006;70:851-9

McGeer PL, McGeer EG, Suzuki J, Dolman CE, Nagai T. Aging, Alzheimer's disease, and the cholinergic system of the basal forebrain. Neurology 1984;34:741-5

Mousavi M, Hellstrom-Lindahl E, Guan ZZ, Shan KR, Ravid $R$, Nordberg A. Protein and mRNA levels of nicotinic receptors in brain of tobacco using controls and patients with Alzheimer's disease. Neuroscience 2003;122:515-20

Muir JL. Acetylcholine, aging, and Alzheimer's disease. Pharmacol Biochem Behav 1997;56:687-96 
Newhouse PA, Potter A, Levin ED. Nicotinic system involvement in Alzheimer's and Parkinson's diseases. Implications for therapeutics. Drugs Aging 1997;11:206-28

Oddo S, LaFerla FM. The role of nicotinic acetylcholine receptors in Alzheimer's disease. J Physiol Paris 2006;99: 172-9

O'Neill MJ, Murray TK, Lakics V, Visanji NP, Duty S. The role of neuronal nicotinic acetylcholine receptors in acute and chronic neurodegeneration. Curr Drug Targets CNS Neurol Disord 2002;1:399-411

Park HJ, Lee PH, Ahn YW, Choi YJ, Lee G, Lee DY, Chung ES, Jin BK. Neuroprotective effect of nicotine on dopaminergic neurons by anti-inflammatory action. Eur $\mathrm{J}$ Neurosci 2007;26:79-89

Parvathenani LK, Tertyshnikova S, Greco CR, Roberts SB, Robertson B, Posmantur R. P2X7 mediates superoxide production in primary microglia and is up-regulated in a transgenic mouse model of Alzheimer's disease. J Biol Chem 2003;278:13309-17

Qin L, Liu Y, Cooper C, Liu B, Wilson B, Hong JS. Microglia enhance $\beta$-amyloid peptide-induced toxicity in cortical and mesencephalic neurons by producing reactive oxygen species. J Neurochem 2002;83:973-83

Seo DR, Kim KY, Lee YB. Interleukin-10 expression in lipopolysaccharide-activated microglia is mediated by extracellular ATP in an autocrine fashion. Neuroreport 2004;15:1157-61

Shimohama S, Tanino H, Kawakami N, Okamura N, Kodama H, Yamaguchi T, Hayakawa T, Nunomura A, Chiba S, Perry
G. Activation of NADPH oxidase in Alzheimer's disease brains. Biochem Biophys Res Commun 2000;273:5-9

Shytle RD, Mori T, Townsend K, Vendrame M, Sun N, Zeng J, Ehrhart J, Silver AA, Sanberg PR, Tan J. Cholinergic modulation of microglial activation by $\alpha 7$ nicotinic receptors. J Neurochem 2004;89:337-43

Sultana R, Perluigi M, Butterfield DA. Protein oxidation and lipid peroxidation in brain of subjects with Alzheimer's disease: insights into mechanism of neurodegeneration from redox proteomics. Antioxid Redox Signal 2006;8:202137

Suzuki T, Hide I, Matsubara A, Hama C, Harada K, Miyano $\mathrm{K}$, Andra M, Matsubayashi H, Sakai N, Kohsaka S. Microglial $\alpha 7$ nicotinic acetylcholine receptors drive a phospholipase C/IP3 pathway and modulate the cell activation toward a neuroprotective role. J Neurosci Res 2006;83:1461-70

Takahashi HK, Iwagaki H, Hamano R, Yoshino T, Tanaka N, Nishibori M. Effect of nicotine on IL-18-initiated immune response in human monocytes. Leukoc Biol 2006;80:138894

Terry AV Jr, Buccafusco JJ. The cholinergic hypothesis of age and Alzheimer's disease-related cognitive deficits: recent challenges and their implications for novel drug development. J Pharmacol Exp Ther 2003;306:821-7

Wang H, Yu M, Ochani M, Amella CA, Tanovic M, Susarla S, Li JH, Wang H, Yang H, Ulloa L. Nicotinic acetylcholine receptor $\alpha 7$ subunit is an essential regulator of inflammation. Nature 2003;421:384-8 